\title{
BIOPODER E MÍDIA: A POLÍTICA DO FAZER VIVER SE RENOVA E ATINGE A MASSA
}

\author{
JEFERSON BERTOLINI \\ UNIVERSIDADE FEDERAL DE SANTA CATARINA \\ SÃO JOSÉ, SANTA CATARINA, BRASIL \\ E-MAIL: JEFERSONBERTOLINI@GMAIL.COM
}


Resumo: Este artigo aborda o conceito de biopoder de Michel Foucault e o relaciona aos meios de comunicação. O texto diz que o governo da vida encontrou na mídia um canal para levar a política do fazer viver às massas. $O$ manuscrito alerta para o nascimento de um fazer viver moderno, e questiona se esse fazer viver não resulta em novo tipo de racismo: do corpo ideal, que exclui o gordo e o sedentário.

Palavras-chave: Biopoder; Mídia; Fazer viver; Racismo.

BIOPODER Y MEDIOS: EL GOBIERNO DE LA VIDA SE RENUEVA Y LLEGA AL PÚBLICO EN GENERAL

Resumen: Esteartículo utiliza el concepto de biopoder de Foucault en el contexto de los medios. El texto sugiere que el gobierno la vida utiliza los medios para propagar sus políticas al público. La alerta manuscrito al nacimiento de un habitus moderna, centrada en el cuerpo, y se pregunta si este habitus no da lugar a nuevo tipo de racismo: el cuerpo ideal, que excluye la grasa y elsedentarismo. Palabras clave: Biopoder; Medios; Cuerpo; Racismo.

\title{
BIOPOWER AND MEDIA: THE POLICY OF DO LIVE IS RENEWED AND REACHES THE MASS
}

\begin{abstract}
This article reviews the concept of biopower of Michel Foucault and relates this concept to the media. The text shows that this form of governing life found in television, radio, newspapers, magazines and internet a channel to reach the mass. The manuscript indicates that the government of life gained power with the media, and warns that this phenomenon represents a new form of racism.
\end{abstract}

Keywords: Biopower; Media; Power of live; Racism. 


\section{INTRODUÇÃO}

Tinha sangue, vísceras e corpos esquartejados no espetáculo da morte: o infrator era puxado por um cavalo até suas pernas se desprenderem do corpo; ou tinha a barriga aberta para que fígado e estômago fossem arrancados à mão; também podia ser decapitado para sua cabeça rolar diante do público. A vontade do soberano era, assim, mais uma vez cumprida.

O show macabro do fazer morrer era comum até o século 17. Depois, como observa Foucault (2012), a morte começa a ser pensada como motivo de vergonha ou falha humana. E inicia-se um movimento em prol de seu oposto, a vida. Surge, então, o biopoder. Inaugura-se um governo da vida. Abre-se a era do fazer viver.

O objetivo era prolongar a vida, torná-la mais produtiva e criar uma população seleta, em um modelo compatível com o evolucionismo de Darwin. Agora, com características renovadas, esse governo da vida se aproxima dos meios de comunicação, se potencializa e leva o fazer viver às massas.

Nesse fazer viver moderno tudo que parece ser contra a vida tornou-se proibido: não se pode mais comer coxinha de galinha porque fritura faz mal ao coração; é pecado beber Coca-Cola porque refrigerante tem açúcar demais e pode provocar derrame cerebral; bacon mata; ovo engorda; farinha branca também; sal aumenta a pressão.

Por outro lado, aquilo que é a favor da vida consolida-se como obrigatório: é preciso comer o talo da couve, a casca da maçã, a semente do mamão; é bom usar filtro 60, almoçar chicória e jiló, beber suco detox para eliminar toxinas; é importante limpar o ar-condicionado, usar álcool gel, tomar sol no fim da tarde, caminhar de tênis com molas, repor hormônios.

Os meios de comunicação de massa ${ }^{24}$ têm um papel determinante nesse fazer viver moderno: é por meio deles que o público destrincha os segredos do corpo perfeito. A pauta está no programa matinal, nos debates da noite, nas revistas à venda em supermercado, nos blogs de nutrição. Instalou-se até no noticiário conservador.

Este artigo apresenta o conceito de biopoder de Foucault e busca en-

24 Os meios de comunicação de massa englobam televisão, rádio, jornal e internet. Juntos formam a mídia. A televisão foi criada em 1925 (ao Brasil, chegou em 1950). O rádio surgiu em 1906 (1922, no Brasil). Os jornais surgiram em 1609, mas só ganharam corpo após a Revolução Industrial e atingiram a massa no século 20. A internet se popularizou nos anos 1990 (BRIGGS \& BURKE, 2006). 
Biopoder e mídia: a política do fazer viver se renova e atinge a massa

xergá-lo entre os meios de meios de comunicação. O objetivo é (1) alertar sobre o governo da vida, com suas táticas finas para controlar os corpos, e (2) fazer refletir sobre a política do fazer viver, que em nosso tempo parece buscar indivíduos capazes de viver mais para (a) trabalhar mais e (b) para consumir mais, dentro de uma lógica capitalista.

Inicialmente o texto avalia o tema na grade da Rede Globo, a maior emissora de televisão do Brasil, com destaque ao programa Bem Estar. Depois aborda tópicos marcantes do biopoder, como disciplina (controle do corpo) e biopolítica (normação da espécie humana).

O manuscrito sugere que, antes de o público atentar para o biopoder infiltrado nos meios de comunicação, são os profissionais que atuam nesses veículos, sobretudo os jornalistas, que devem ser alertados do fenômeno. Afinal, uma das principais características do biopoder é a discrição.

\section{O GOVERNO DA VIDA NA TELA DA TV}

Os meios de comunicação de massa têm, de maneira resumida, dois campos de atuação: o entretenimento, que se verifica em programas de auditório e afins; e o jornalismo, que idealmente deve fornecer informações de qualidade para que as pessoas sejam livres e se autogovernem (Kovach \& Rosenstiel, 2003).

Na Rede Globo, avaliada aqui por ser a maior do Brasil, há esta distinção. Nela, os programas que buscam aumentar as potencialidades do corpo ganharam tanta projeção que estão nos dois campos de atuação: discute-se temas como a importância de comer salada, de fazer exercício físico, de beber água e de usar filtro solar tanto em programas de entretenimento, como o Mais Você, quanto em programas jornalísticos, como o Globo Repórter.

Um exemplo notório da pauta do corpo ideal em programas jornalísticos verificou-se entre 2012 e 2014 no Fantástico. No quadro Medida Certa, anônimos e famosos foram submetidos a esquemas de exercícios físicos e de controle da alimentação para perder peso. O verbo emagrecer predominou na pauta e na rua, já que os participantes percorreram as principais capitais do país estimulando o público a aderir à campanha.

O sucesso de quadros dessa natureza fez a emissora criar o Bem Estar, um programa exclusivo para tratar do assunto. Com 45 minutos de duração, a atração vai ao ar diariamente e busca, em essência, ensinar o público a cuidar do corpo. Jornalistas e médicos falam ao vivo sobre temas como fun- 
cionamento do intestino, entupimento das artérias do coração, respiração, calvície, consumo de remédios, depilação, postura do corpo, alimentos calóricos, glúten, espinhas, lactose etc. A regra, como verificou-se após a observação ${ }^{25}$ de 64 programas exibidos entre outubro e dezembro de 2014, é estimular o cuidado de si, sem refletir acerca do porquê devemos viver mais.

Com frequência, o programa apresenta histórias de telespectadores que emagreceram até 30 quilos com dietas, como se emagrecer devesse se converter em regra. Também associa qualidade de vida à perda de peso, como se indivíduos com massa corpórea acima do recomendado por órgãos internacionais de saúde fossem doentes. Chamadas como "obesos precisam mudar hábitos" ou "crianças devem levar frutas" para comer no lanche são comuns. Há, do ponto de vista de Foucault, uma nítida infiltração de estratégias biopolíticas na pauta do programa. O público percebe? Os jornalistas percebem? Para se aproximar desta questão, é preciso antes entender como se desenvolveu o biopoder.

\section{O SURGIMENTO DO BIOPODER}

Biopoder é uma forma de governar a vida posta em prática a partir do século 17. Divide-se em dois eixos: disciplinas (governo do corpo dos indivíduos) e biopolítica (governo da população como um todo).

Antes dele predominava o poder soberano, que dispunha do direito de vida e de morte sobre os súditos e operava pelo fazer morrer e pelo deixar viver. Era inspirado na pátria potestas, um mecanismo que concedia ao pai de família romano o direito de dispor da vida dos filhos, uma vez que a tinha dado.

Essa forma soberana de governo acabou. O poder de morte converteu-se no "complemento de um poder que se exerce positivamente sobre a vida", interferindo em "sua gestão, majoração e multiplicação". Transformou-se no exercício, sobre a vida, "de controles precisos e regulações de conjunto" (FOUCAULT, 2012, p. 129).

Como observa o autor (Ibid), "as guerras já não se travam em nome do

25 A observação, explica Abramo (1979), permite que o pesquisador assista ao fenômeno estudado e registre suas observações onde mais lhe convier. Em nosso trabalho, a observação foi feita após levantamento bibliográfico. Como pontua Fonseca (2002), o levantamento de referências teóricas é básico para qualquer trabalho científico porque permite ao pesquisador conhecer o que já se estudou sobre o assunto (em nosso caso, o biopoder). 
soberano a ser defendido; travam-se em nome da existência de todos; populações inteiras são levadas à destruição mútua em nome da necessidade de viver. Os massacres se tornaram vitais".

Assim, "o princípio de poder matar para poder viver, que sustentava a tática dos combates, tornou-se princípio de estratégia entre estados; mas a existência em questão já não era aquela jurídica da soberania, era outra: biológica, da população" (Ibid, p. 129). Dito de outra forma, o direito de causar a morte ou deixar viver foi substituído pelo poder de causar a vida. Esse poder sobre a vida desenvolveu-se em duas formas principais.

A primeira, a partir do século 17, centrou-se no corpo como máquina. Focava seu adestramento. Agia na ampliação de suas aptidões, na extorsão de suas forças, no crescimento paralelo de sua utilidade e docilidade, na sua integração em sistemas de controle eficazes e econômicos. Tudo era assegurado por procedimentos de poder que caracterizam o que o autor chama de disciplinas: anátomo-política do corpo humano.

A segunda, a partir da segunda metade do século 18, centrou-se no coletivo. Ou, como define o autor, "no corpo transpassado pela mecânica do ser vivo como suporte dos processos biológicos"; no controle da proliferação, dos nascimentos, da mortalidade, do nível de saúde, da duração da vida, da longevidade com todas as condições que podem fazê-los variar. Tais processos são assumidos mediante toda uma série de intervenções e controles reguladores: uma biopolítica da população.

Ele resume as duas formas desse poder sobre a vida:

As disciplinas do corpo e as regulações da população constituem os dois polos em torno dos quais se desenvolveu a organização do poder sobre a vida. A instalação, durante a época clássica, desta tecnologia de duas faces - anatômica e biológica -, individualmente e especificante, voltada para os desempenhos do corpo e encarando os processos da vida, caracteriza um poder cuja função mais elevada já não é mais matar, mas investir sobre a vida, de cima para baixo (FOUCAULT, 2012, p.131).

Como observa o autor (Ibid), é no desenvolvimento rápido, no decorrer da época clássica, das disciplinas diversas, como escolas, colégios e casernas; e no aparecimento, no terreno das práticas políticas e observações econômicas, dos problemas de natalidade, longevidade, saúde pública, habitação e migração; e na explosão de técnicas diversas para se obter a sujeição dos corpos e o controle das populações, que se abre a era do biopoder. 
No século 18, as duas formas que configuram esse poder operavam separadas: do lado da disciplina, predominavam instituições como o Exército e valorizavam-se as reflexões sobre a tática, a aprendizagem e a adequação sobre a ordem das sociedades; do lado da regulação das populações (biopolítica) estavam a demografia, a estimativa da relação entre recursos e habitantes, a tabulação das riquezas e sua circulação.

Para Foucault (Ibid, p. 132), este biopoder, "sem a menor dúvida, foi elemento indispensável ao desenvolvimento do capitalismo, que só pôde ser garantido à custa da inserção controlada dos corpos nos aparelhos de produção e por meio de um ajustamento de fenômenos de população aos processos econômicos".

Como salienta o autor, outra consequência do desenvolvimento do biopoder foi a importância crescente assumida pela atuação da norma, atrelada ao sistema jurídico da lei. "A lei não pode deixar de ser armada, e sua arma por excelência é a morte; aos que a transgridem, ela responde, pelo menos como último recurso, com esta ameaça absoluta." (Ibid, p. 135). Ele completa: "a lei sempre se refere ao gládio (espada, símbolo do julgamento romano). Mas um poder que tem a tarefa de se encarregar da vida terá necessidade de mecanismos contínuos, reguladores e corretivos." E finaliza: "uma sociedade normalizadora é o efeito histórico de uma tecnologia de poder centrada na vida."

\section{DISCIPLINA: ANATOMIA POLÍTICA E O CONTROLE SOBRE O CORPO}

No século 18, a figura do soldado, tido como biotipo ideal e cidadão valente, despertou nos camponeses europeus a vontade de também ser viril e heroico. Nas palavras de Foucault (2013, p. 131), aquele que "leva os sinais naturais de seu vigor e coragem" e cujo corpo "é o brasão de sua força e valentia" se tornou "algo que se fabrica" e se imita.

De uma massa informe, de um corpo inapto, fez-se a máquina de que se precisa; corrigiram-se aos poucos as posturas: lentamente uma coação calculada percorre cada parte do corpo, assenhoreia-se dele, dobra o conjunto, torna-o perpetuamente disponível, e se prolonga, em silêncio, no automatismo dos hábitos; em resumo, foi expulso o camponês e lhe foi dada a fisionomia de soldado (Ibid). 
Na época, o corpo foi alvo de uma valorização como nunca se havia visto antes. Transformou-se naquilo que o autor chamou de "objeto de investimentos tão imperiosos e urgentes". Por outro lado, também se tornou alvo de controle:

O corpo está preso no interior de poderes muito apertados, que Ihe impõem limitações, proibições ou obrigações. Muitas coisas são novas nessas técnicas. A escala, em primeiro lugar, do controle: não se trata de cuidar do corpo, em massa, grosso modo, como se fosse uma unidade indissociável, mas de trabalhá-lo detalhadamente; de exercer sobre ele uma coerção sem folga, de mantê-lo ao mesmo nível da mecânica - movimentos, gestos, atitude, rapidez: poder infinitesimal sobre o corpo ativo (Ibid, p.132).

Foucault via ali o controle "não dos elementos significativos do comportamento ou a linguagem do corpo, mas a economia, a eficácia dos movimentos, sua organização interna" (Ibid). Tratava-se, segundo o autor, de uma coerção ininterrupta e constante que levava em conta o tempo, o espaço e os movimentos. Vem desse processo a ideia de disciplina, que ele define como "métodos que permitem o controle minucioso das operações do corpo, que realizam a sujeição constante de suas forças e lhes impõem uma relação de docilidade-utilidade" (Ibid). O autor lembra que muitos processos disciplinares existiam havia muito tempo: nos conventos, nos exércitos, nas oficinas. Mas em sua perspectiva as disciplinas se tornaram, no decorrer dos séculos 17 e 18, formulas gerais de dominação.

O momento histórico das disciplinas é o momento em que nasce uma arte do corpo humano, que visa não unicamente o aumento de suas habilidades, nem tampouco aprofundar sua sujeição, mas a formação de uma relação que no mesmo mecanismo o torna tanto mais obediente quanto é mais útil, e inversamente. Forma-se, então, uma política das coerções, que são um trabalho sobre o corpo, uma manipulação calculada de seus elementos, de seus gestos, de seus comportamentos (Ibid, p. 133).

Surge, então, a noção de anatomia política:

O corpo humano entra numa maquinaria de poder que o esquadrinha, o desarticula e o recompõe. Uma anatomia política, que é também igualmente uma mecânica do poder, está nascendo; ela define como se pode ter poder sobre o corpo dos outros, não simplesmente para que façam o que se quer, 
mas para que operem como se quer, com as técnicas, segundo a rapidez e a eficácia que se determina. A disciplina fabrica assim corpos submissos e exercitados, corpos dóceis. A disciplina aumenta as forças do corpo (em termos econômicos de utilidade) e diminui essas mesmas forças (em termos políticos de obediência) (Ibid, p. 133-134).

A invenção dessa nova anatomia política, diz Foucault (Ibid, p. 134), "não deve ser entendida como uma descoberta súbita". Mas como "uma multiplicidade de processos muitas vezes mínimos, de origens diferentes, de localizações esparsas, que se recordam, se repetem, apoiam-se uns sobre os outros (...) e esboçam aos poucos a fachada de um método geral”.

\section{BIOPOLÍTICA: A NORMACÃO DA ESPÉCIE HUMANA}

A biopolítica, percebida com mais nitidez na segunda metade do século 18 , se aplica à vida dos homens. Opera pela norma, o mecanismo que separa o normal do anormal, em dois sentidos: norma estatística (maioria) e como parâmetro moral.

Para Foucault (2005, p. 289), essa nova tecnologia não exclui a técnica disciplinar, vista anteriormente, porque "é de outro nível, está em outra escala, tem outra superfície de suporte e é auxiliada por instrumentos totalmente diferentes". Mas "a embute, a integra, a modifica parcialmente e, sobretudo, vai utilizá-la implantando-se de certo modo nela, e incrustando-se efetivamente graças a essa técnica disciplinar prévia".

A disciplina tenta reger a multiplicidade dos homens na medida em que essa multiplicidade pode e deve redundar em corpos individuais que devem ser vigiados, treinados, utilizados, punidos. E, depois, a nova tecnologia que se instala se dirige à multiplicidade dos homens, não na medida em que eles se resumem em corpos, mas na medida em que ela forma, ao contrário, uma massa global, afetada por processos de conjunto que são próprios da vida, que são processos como o nascimento, a morte, a produção, a doença (Ibid).

O autor diz que a primeira (disciplina) é individualizante, porque foca no corpo; a segunda (biopolítica) é massificante, porque concentra-se na espécie. Sobre o surgimento da biopolítica, ele diz: “Depois da anátomo-política 
Biopoder e mídia: a política do fazer viver se renova e atinge a massa

do corpo humano, instaurada no decorrer do século 18, vemos aparecer, no fim do mesmo século, algo que já não é uma anátomo-política do corpo humano, mas que eu chamaria de uma biopolítica da espécie humana." (Ibid)

Para Foucault, a biopolítica se encarregou inicialmente de processos como a proporção dos nascimentos, a taxa de reprodução, a fecundidade de uma população. "São esses processos de natalidade, de mortalidade, de longevidade que, juntamente com uma porção de problemas econômicos e políticos, constituíram os primeiros objetos de saber e os primeiros alvos de controle dessa biopolítica" (Ibid, p. 290).

É nesse contexto que se verifica uma atenção especial ao combate às pragas e às epidemias que ameaçavam a população, diminuíam o tempo de trabalho, traziam custos econômicos e freavam a produção. A medicina, então, ganha espaço. E se encarrega da higiene pública.

Foucault diz que a biopolítica lida com um novo corpo, um corpo múltiplo, de inúmeras cabeças: a população. "A população como problema político, como problema a um só tempo científico e político, como problema biológico e como problema de poder, acho que aparece nesse momento" (Ibid, p. 292-293).

O autor observa que essa tecnologia de poder criou mecanismos que tratam, sobretudo, de previsões, estimativas estatísticas e medições globais. Em outras palavras, a biopolítica implantou regulações que buscam otimizar um estado de vida: "A soberania fazia morrer e deixava viver. E eis que agora aparece um poder, que eu chamaria de regulamentação, e que consiste, ao contrário, em fazer viver e deixar morrer" (Ibid, p. 294).

\section{RISCO E IMPRENSA: A AMEAÇA DEVE SER CALCULADA E COMUNI- CADA}

Como objetiva fazer viver, o governo da vida deve afastar aquilo que pode fazer morrer. Logo, precisa calcular o risco de tudo que é indesejado, de um ataque terrorista às taxas de gordura no sangue. Vivemos, como disse Beck (2010), na sociedade de risco.

Para Foucault, risco são as ameaças que acompanham a humanidade. E é nesse ponto que se verifica uma das funções dos meios de comunicação de massa: tornar o risco perceptível entre as massas.

Assim, atualmente, deve-se explicar o glúten, a lactose, a importância do funcionamento do intestino. A pauta, seja nos programas de entreteni- 
mento ou nos veículos jornalísticos, precisa falar dos benefícios da linhaça, do suco da berinjela, da importância do sono, do sexo com camisinha; em resumo, deve aproximar a vida e afastar a morte.

Essa onda em favor da vida reconfigura a programação da tevê (há até programas exclusivos sobre essa temática) e do rádio (saúde é assunto predominante principalmente nos quadros de entrevista). Também altera a pauta do jornal (antes o tema era publicado em uma página semanal, agora tem editoria chamada Vida e Saúde), cria revistas temáticas (saiba como perder três quilos em uma semana é a manchete de muitas delas) e aumenta o tráfego na internet (como emagrecer é um dos temas mais procurados no Google).

Alertar sobre os riscos é uma tarefa fácil para os meios de comunicação de massa. Afinal, a busca por informação é algo tão antigo quanto à própria humanidade.

Kovach e Rosenstiel (2003, p. 17) afirmam que "as pessoas buscam informação por causa de um instinto básico do ser humano". Elas "precisam saber o que acontece do outro lado do país e do mundo, estar a par de fatos que vão além de sua experiência" porque "o conhecimento do desconhecido lhes dá segurança, permite-lhes administrar suas vidas".

Nos meios de comunicação, a notícia ${ }^{26}$ é o instrumento mais usado e confiável para informar o público de algo. Há grande interesse por esse tipo de conteúdo. "As pessoas estão interessadas em notícia o tempo inteiro"27 . Não importa se elas vêm de outras pessoas ou de veículos de massa, todos querem saber o que está acontecendo em lugares distantes ou com seus vizinhos" (SHOEMAKER; COHEN, 2006, p. 3).

Stephens (1988) e Traquina (2004) acrescentam que, ao longo da his-

26 Definições clássicas reunidas em Lage (2002): "Se o cachorro morde um homem, não é notícia; mas se um homem morde o cachorro, aí, então, a notícia é sensacional (AMUS CUMMINGS); “É algo que não se sabia ontem” (TURNER CATLEDGE); “É uma compilação de fatos e eventos de interesse ou importância para os leitores do jornal que a publica” (NEIL MACNEIL); “É tudo o que o público necessita saber; tudo que o público deseja falar; quanto mais comentário suscite, maior é seu valor" (COLLIERS WEKLY); “Informação atual, verdadeira, carregada de interesse humano e capaz de despertar a atenção de muitas pessoas" (AMARAL).

27 Park (1945) diz que a notícia é tão velha quanto à própria humanidade. E, se entendida como forma de conhecimento, existe até entre outras espécies. "Os animais inferiores não estavam isentos do tipo de comunicação que não é diferente da notícia. O cacarejar da galinha mãe é entendido pelos pintos como sinal de perigo ou comida, e os pintos reagem de acordo". 
Biopoder e mídia: a política do fazer viver se renova e atinge a massa

tória, a morte apareceu como tema de forte interesse do público ${ }^{28}$. Pois, por meio dela, sabe-se também sobre a vida: aprende-se a preservá-la e a valorizá-la.

\section{TEORIAS DA COMUNICAÇÃO E DO JORNALISMO NÃO FOCAM O BIO- PODER}

A preocupação com o efeito da comunicação na vida humana é antiga. Surgiu com Aristóteles e seus estudos sobre retórica. Mas as teorias a respeito dos meios de comunicação de massa e seus impactos só surgiram no século 20 (WOLF, 1995), a partir do uso do rádio por Ritler ${ }^{29}$. Nenhuma foca diretamente o biopoder.

As primeiras teorias foram a hipodérmica (a informação atinge a massa de maneira idêntica e sem resistência), a de Lasswell (o público é uma massa passiva que só reage aos estímulos) e a da persuasão (o conteúdo é absorvido de maneira distinta pelo público, de acordo com perspectivas pessoais).

As seguintes foram a teoria empírica de campo (a mídia tem uma influência limitada sobre a massa, como a escola, a Igreja ou a política), a funcionalista (foca o papel da mídia na sociedade, não seus efeitos), a crítica (vê a mídia como instrumento de influência capitalista) e a culturológica (a mídia não produz cultura de massa, mas se baseia em padrões sociais existentes, que surgem da cultura).

O jornalismo, que busca uma independência da comunicação e reivindica para si uma ciência particular, baseada nos jornais (GROTH, 2011), também tem suas teorias (TAQUINA, 2004). E nenhuma esquadrinha o governo da vida.

As primeiras foram a do espelho (as notícias são como são porque a realidade assim as determina), a do gatekeeping (coloca o jornalismo como o guardião do portão por onde passam as notícias), a organizacional (o jornalismo é um mercado e as notícias são seus produtos) e a do agenda setting (a agenda dos meios influencia na agenda pública).

28 Outros elementos que atraem o público são a relevância, a notoriedade, a proximidade, a novidade, o tempo, a notabilidade, o inesperado, o conflito ou controvérsia, a infração e o escândalo (Ibid). No jornalismo, esses elementos são chamados de valores de notícia.

29 O rádio, então um veículo de comunicação novo, era visto pelo ministro da Propaganda, Josef Goebbels, como meio ideal para controlar e divulgar o ideário nazista. 
Depois vieram as teorias instrumentalista (sobre o conteúdo das notícias: os esquerdistas dizem que há manipulação para sustentar o modelo capitalista; os direitistas dizem que as notícias questionam o capital), dos definidores primários (as notícias são distorcidas, não pelos jornalistas ou donos do jornal, mas pelas fontes) e a do newsmaking (a produção da notícia é elaborada como processo industrial).

Há ainda a unificadora (critica as anteriores por não explicar o que são as notícias, porque as notícias são como são e qual o efeito delas), a multifatorial (vê a notícia como produto da integração histórica e presente de forças pessoais, sociais, ideológicas, culturais) e a espiral do silêncio (explica a influência da opinião pública na opinião de cada indivíduo).

Nesse contexto, convém perguntar: os meios de comunicação percebem alguma estratégia biopolítica nos conteúdos que veiculam? É importante lembrar que a discrição é uma das principais características do biopoder: ele age diluído em mecanismos de governo, ao contrário de seu antecessor, o poder soberano, que agia explicitamente.

\section{CONSIDERAÇÕES FINAIS}

O jornalismo é dividido em gêneros: artigo, resenha, crônica, reportagem, notícia etc. Nos últimos anos, o gênero que mais se desenvolveu foi o chamado jornalismo de serviço, voltado à orientação e dicas ao público. Entram, em sua grade de assuntos, temas como previsão do tempo, condições do trânsito, agenda de shows no verão, o que abre e o que fecha nos feriados etc.

O termo ${ }^{30}$, criado nos anos 1950, é alvo de críticas por suposto elo com o capitalismo (na ideia de serviço estaria a orientação para o consumo). Melo (2007) lembra que este gênero surgiu com o advento da sociedade da informação, cujo funcionamento repousa na tomada de decisões rápidas, e observa que é mais usado nos países mais consumistas.

Aqui, a pergunta que cabe é: estariam os meios de comunicação, por meio do jornalismo de serviço ou de outro gênero, ajudando a promover uma política da vida em nosso tempo? O questionamento mais pertinente, no entanto, está no efeito, sobre o público, deste fazer viver moderno:

30 Há entre os estudiosos do jornalismo uma corrente que considera o termo redundante, uma vez fornecer informações ao público é função básica do jornalismo (MELO, 2007). 
estaríamos diante de um novo tipo de racismo? Um racismo que considere ideal o sujeito com corpo magro e esguio e que condene quem está acima do peso e se declare sedentário?

Foucault (2005, p. 228) argumenta que o nazismo, uma experiência catastrófica da humanidade que excluía raças consideradas impuras, foi possível a partir do biopoder. "Na medida em que seus mecanismos são usados para exercer o direito soberano de fazer morrer ou deixar viver, a biopolítica se converte em uma política de morte."

Para o autor, a teoria evolucionista, de Darwin, e a teoria da degeneração, de Morel, conferiram sentido biológico ao conceito de raça. Com isso, a função de morte do direito soberano (século 17) já não está dirigida ao inimigo político, mas ao biológico (atual).

Nesse contexto, observa Foucault, a destruição das outras raças é só um dos objetivos do racismo; o outro é a regeneração da própria raça, mesmo que ela seja exposta à morte.

Foucault (Ibid, p. 230-304-309) sustenta que "o racismo moderno não é nem uma velha tradição, nem uma nova ideologia, mas uma tecnologia do poder". E observa que, apesar de o racismo ser mais antigo que a época do soberano, "o que o inseriu nos mecanismos de Estado foi mesmo a emergência desse biopoder”.

\begin{abstract}
Como, nessas condições, é possível, para um poder político, matar, reclamar a morte, pedir a morte, mandar matar, dar ordem de matar, expor à morte não só seus inimigos, mas seus próprios cidadãos? Como esse poder que tem essencialmente o objetivo de fazer viver pode deixar morrer? Como exercer o poder da morte, como exercer a função da morte, num sistema político centrado no biopoder? É, aí, creio eu, que intervém o racismo (Ibid, p. 304).
\end{abstract}

Foucault diz que o racismo é "o meio de introduzir, nesse domínio da vida de que o poder se incumbiu, um corte: o corte entre o que deve viver e o que deve morrer" (Ibid, 304). Sustenta que a primeira função do racismo é "fragmentar, fazer censuras no interior desse contínuo biológico a que se dirige o biopoder"; a segunda é estabelecer uma espécie de relação outrora guerreira (para viver, é preciso que você massacre seus inimigos) em sentido biológico: "Quanto mais as espécies inferiores tenderem a desaparecer, quanto mais os indivíduos anormais forem eliminados, menos degenerados haverá em relação à espécie, mais eu viverei, mais forte serei, mais vigoroso serei, mais poderei proliferar" (Ibid, p. 305). 
Foucault (Ibid, p. 306) entende que "tirar a vida, o imperativo da morte, só é admissível, no sistema de biopoder, se tende não à vitória sobre os adversários políticos, mas à eliminação do perigo biológico e ao fortalecimento da própria espécie ou da raça. A raça, o racismo, é a condição de aceitabilidade de tirar a vida numa sociedade de normalização".

Por fim, afirma que o racismo "é ligado ao funcionamento de um Estado que é obrigado a utilizar a raça, a eliminação das raças e a purificação da raça para exercer seu poder soberano".

Nesse contexto, convém perguntar: o conteúdo em favor da vida que predomina na mídia não estaria ajudando a formatar uma raça do corpo ideal? 
Biopoder e mídia: a política do fazer viver se renova e atinge a massa

\section{REFERÊNCIAS}

ABRAMO, Perseu. Pesquisa em ciências sociais. In: Pesquisa social; projeto e planejamento. SP, Queiroz Editor, 1979. p. 21-44.

BECK, Ulrich. Sociedade de risco: rumo a uma outra modernidade; tradução de Sebastião Nascimento. 2. ed. São Paulo: Editora 34, 2010

BRIGGS, Asa; BURKE, Peter. Uma história social da mídia: de Gutenberg à internet. 2. ed. Rio de Janeiro: Zahar, 2006

CASTRO, Edgardo. Introdução a Foucault; tradução de Beatriz de Almeida Magalhães. 1. ed. Belo Horizonte: Autêntica, 2014

FONSECA, João José. Metodologia da pesquisa científica. Fortaleza: UEC, 2002. Apostila. FOUCAULT, Michel. História da sexualidade I: a vontade de saber; tradução de Maria Thereza da Costa Albuquerque e J. A. Guilhon Albuquerque. 22. ed. Rio de Janeiro: Graal, 2012

. Vigiar e punir: história da violência nas prisões; tradução de Raquel Ramalhete.

41. ed. Petrópolis: Vozes, 2013

. Em Defesa da Sociedade. São Paulo: Martins Fontes, 2005

. Segurança, Território, População. São Paulo: Martins Fontes, 2009

GROTH, Otto. O poder cultural desconhecido: fundamentos da ciência dos jornais. Tradução de Liriam Sponholz. Petrópolis: Vozes, 2011

KAPUSCINSKI, Ryszard. Minhas viagens com Heródoto: entre a história e o jornalismo.

São Paulo: Companhia das Letras, 2006

KOVACH, Bill; ROSENSTIEL, Tom. Os elementos do jornalismo: o que os jornalistas devem saber e o público exigir. 2. ed. São Paulo: Geração Editorial, 2003

LAGE, Nilson. Estrutura da notícia. São Paulo: Ática, 2002

MELO, José marques. Gêneros de comunicação massiva. São Bernardo do Campo: Metodista, 2007

PARK, Robert. A notícia como forma de conhecimento (1945). In. BERGER, Christa; MAROCCO, Beatriz. (orgs). A Era Glacial do Jornalismo. Porto Alegre: Sulina, 2008. 33-50

RODRIGUES, Nina. Mestiçagem, degenerescência e crime. In: História, Ciência, Saúde-Manguinhos, Rio de Janeiro, v. 15, n. 4, dez. 2008

SHOEMAKER, Pamela; COHEN, Akiba. News around the world. London: Routledge, 2006 STEPHENS, Mitchell. History of news: from the drum to the satellite. Nova York: Viking Press, 1988

TRAQUINA, Nelson. Teorias do Jornalismo: a tribo jornalística, uma comunidade interpretativa internacional. v. 2. Florianópolis: Insular, 2004

WOLF, Mauro. Teorias da comunicação. 5. ed. Lisboa, 1995. 


\section{Jeferson Bertolini}

Jornalista. Doutorando em Ciências Humanas (UFSC), Mestre em Jornalismo (UFSC), Bacharel em Comunicação Social/ Jornalismo (Univali).

RECEBIDO EM: 08/03/2015

APROVADO PARA PUBLICAÇÃO: 06/10/2015 